\title{
ESS \\ Effect of Mechanical Stress on the Properties of Steel Surfaces: Scanning Kelvin Probe and Local Electrochemical Impedance Study
}

\author{
A. Nazarov, ${ }^{\mathrm{a}, *, \mathrm{z}}$ V. Vivier, ${ }^{\mathrm{b}, *}$ D. Thierry, ${ }^{\mathrm{a}, *}$ F. Vucko, ${ }^{\mathrm{a}}$ and B. Tribollet ${ }^{\mathrm{b}, * *}$ \\ ${ }^{a}$ French Corrosion Institute, 29200 BREST, France \\ ${ }^{b}$ Sorbonne Universités, UPMC Université, Paris 06, CNRS, Laboratoire Interfaces et Systèmes Electrochimiques, \\ F-75005 Paris, France
}

\begin{abstract}
The influence of mechanical stress on the electrochemical properties of ferritic steel SAE 1008 and austenitic stainless steel 301LN was studied using Scanning Kelvin Probe and Localized Electrochemical Impedance Spectroscopy (LEIS) techniques. The probeworking electrode Volta potential difference was mapped in situ under load. It was found that the influence of elastic deformation on the potential was small. Plastic deformation decreased the potential of steel by $150-300 \mathrm{mV}$, whereas the relaxation of the load from the plastic domain increased the Volta potential. However, some locations, which can contain residual stress, remained at low potential. The pre-strained surfaces were characterized by X-ray Photo Electronic Spectroscopy and by Atomic Force Microscopy. Distribution of the capacitance across strained and strain-free surfaces was studied by LEIS in boric/borate electrolyte. The plastic stress increases the capacitance and decreases the ability of the steels to passivate the surface indicating that emerging of pile-ups of dislocations create defective oxide films.

(C) The Author(s) 2017. Published by ECS. This is an open access article distributed under the terms of the Creative Commons Attribution 4.0 License (CC BY, http://creativecommons.org/licenses/by/4.0/), which permits unrestricted reuse of the work in any medium, provided the original work is properly cited. [DOI: 10.1149/2.1311702jes] All rights reserved.

(cc) BY
\end{abstract}

Manuscript submitted November 17, 2016; revised manuscript received December 31, 2016. Published January 12, 2017. This was

Paper 1729 presented at the Honolulu, Hawaii, Meeting of the Society, October 2-7, 2016.

Stress corrosion cracking (SCC) is a well-known complex corrosion process caused by the combination of stress and corrosion, which can lead to wear, cracking or fatigue failures. In many cases, the residual stress from plastic deformation or wear accelerates the corrosion rate. ${ }^{1}$ In the classic film rupture model, tensile stress breaks the passive film creating anodic locations at the bottom of the crack, ${ }^{2,3}$ which propagates through an activation/passivation process. This model was developed to the "slip dissolution-film rupture model" pointing out the importance of formation of dislocations and metal dissolution through dislocation slip lines. ${ }^{3,4}$ The slip dissolution-film rupture model of crack advance was discussed in details previously. ${ }^{5}$ This model can predict the crack growth rate for the stainless steels, nickel alloys, and low-alloy steels in high temperature water. ${ }^{6}$

The effect of the yielding on the rate of dissolution of many metals was found to be much pronounced in comparison with the influence of elastic deformation. ${ }^{7}$ The dissolution rate showed a marked rise at the beginning of the plastic region that is asymptotic with increasing strain. Similar effects of plastic deformation on the anodic current during dissolution were also found for stainless steels. ${ }^{8}$ To explain this mechanical- electrochemical effect, both the increase of dissolution rate at slip edges and dislocations, and the increase of surface roughness from plastic deformation were pointed out. ${ }^{8}$ On the other hand, the selective slip dissolution can be ascribed to the local excess of Gibbs potential, ${ }^{7,8}$ thus contradicting earlier works. Hoar ${ }^{9}$ has shown that both enthalpy and entropy of activation were not significantly altered by cold work, which meant that the free energy of activation for anodic reaction should remain almost constant. A calorimetric study ${ }^{10}$ showed that residual energy from cold work was less than 7 calories per gram without any significant impact on Gibbs potential during the deformation.

Interestingly, Sahal et al., ${ }^{11}$ and Saito and Kuniya ${ }^{12}$ reported that elastic (hydrostatic) stress can modify the chemical potential of the dissolving species, and accordingly the energy of activation of the metal dissolution. The dissolution rate in acidic electrolyte was found to be proportional to the dislocation density created by plastic strain. As a result, surface roughness associated with emergence of slip bands promoted the dissolution process in relation with the electronic state of the surface. ${ }^{13}$ The activation energy of the dissolution process can be influenced by long-range internal stresses due to the heterogeneous

\footnotetext{
*Electrochemical Society Member

**Electrochemical Society Fellow.

${ }^{\mathrm{z}}$ E-mail: andrej.nazarov@institut-corrosion.fr
}

distribution of dislocations, evolution of kink density and emergence of the lines of the dislocations, whereas plasticity and formation of dislocations or kinks can modify the solid configurational entropy. ${ }^{13}$ Thus, the activation energy to transfer metallic ions in the electrolyte is decreased by dislocations.

In addition, the properties of the surface oxide film can be modified by plastic strain. A less protective passive film was created by cold working, which was attributed to the presence of defects such as dislocation pile-ups. ${ }^{1,14}$ A study of austenitic stainless steel showed that cold work and plastic deformation lead to the formation of dislocations and $\alpha$-martensite that decreased the ability of the steel to passivation. ${ }^{1,15,16}$ Martensite was formed in deformed areas, where slip planes intercepted the passive film and a large number of dislocations may be concentrated. ${ }^{15}$

Electrochemical Impedance Spectroscopy (EIS) and MottSchottky analysis were shown to be efficient to analyze the semiconducting properties of passive film on stainless steels $(316 \mathrm{~L}$ and 304) under mechanical stress. ${ }^{16,17}$ The conductivity and capacitance of the oxide film increased when an elastic or a plastic stress was applied. This effect was explained by an increase of the concentration of donors and acceptors compared to a stress-free state. Under these conditions, the formation of oxygen vacancies according to the point defect model ${ }^{18}$ was proposed to explain the sensitivity of stainless steel to localized corrosion such as pitting corrosion and stress corrosion cracking. ${ }^{17}$

Thus, the stress can decrease the activation energy of anodic dissolution, which was found during the active dissolution of steel. Moreover, in previous studies, ${ }^{19,20}$ the use of scanning Kelvin probe (SKP) showed that plastic tensile and compressive strain decreased the electrochemical (Volta) potential of stainless steel by $200-300 \mathrm{mV}$. The measurements were performed in air, thus minimizing the influence of adsorption of ions or the hydrogenation on the potential. The straininduced drop of the electrochemical potential was explained by the formation of dislocations that broke the oxide film. However, plastic deformation transforms austenite to martensite phase that can also influence the potential. ${ }^{20}$ Thus, it was important to continue the study and to compare the effect of the stress on the potential of ferritic and austenitic steels. Determination of the potential in the locations containing the residual stress due to previous plastic deformation is also a point of interest. In this work, two complementary local probe techniques with similar level of spatial resolution were used for the characterization of carbon and austenitic steels. SKP was used to measure the electrochemical potential of the surfaces with stress, whereas 
Table I. Chemical compositions of the investigated materials [wt \%].

\begin{tabular}{cccccccccc} 
Material & $\mathrm{Fe}$ & $\mathrm{C}$ & $\mathrm{Si}$ & $\mathrm{Mn}$ & $\mathrm{P}$ & $\mathrm{S}$ & $\mathrm{Cr}$ & $\mathrm{Ni}$ & $\mathrm{Mo}$ \\
\hline 301 LN & Bal. & 0.029 & 0.43 & 1.27 & 0.031 & 0.001 & 17.60 & 6.55 & 0.17 \\
SAE 1008 & Bal. & 0.13 & - & $0.2-0.6$ & - & $<0.05$ & - & - & -
\end{tabular}

a

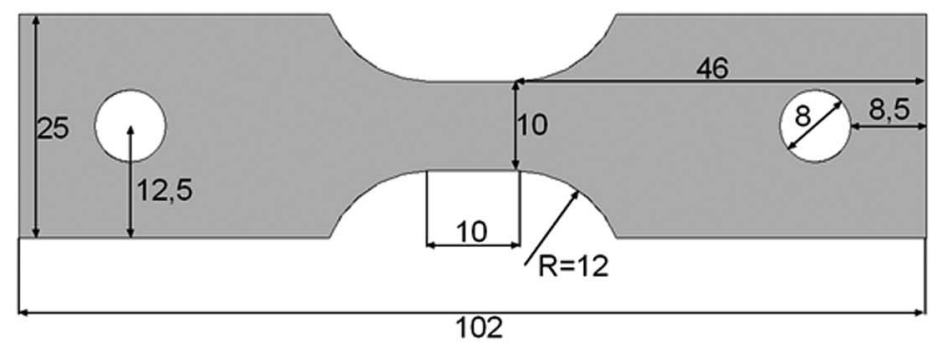

b

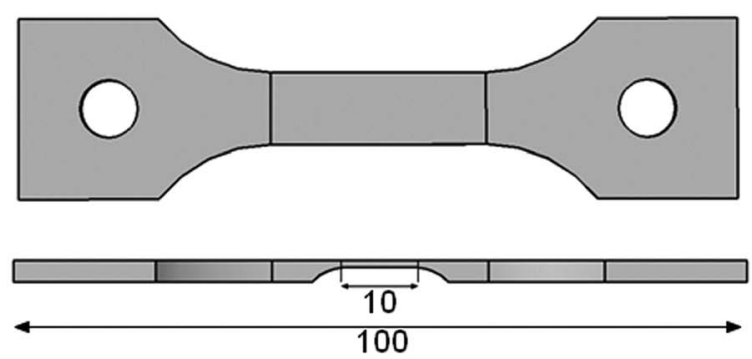

Figure 1. Sketches of the samples used. a- carbon steel sample, b- stainless steel $301 \mathrm{LN}$ sample. The dimensions are given in mm.

local electrochemical impedance spectroscopy (LEIS) was used to characterize the passive films in stressed conditions and the ability of these areas to repassivation. The role of the applied stress on the stability of passive oxide film and the reactivity of the stainless steel surface in aqueous electrolyte was studied using local electrochemical techniques in a preliminary investigation. ${ }^{21}$

\section{Experimental}

Material and specimens.-In this study, carbon steel SAE 1008 and austenitic stainless steel $301 \mathrm{LN}$ (EN 1.4318) were used. The nominal compositions of the two steels are given in Table I. The materials were machined to obtain samples compatible with the local probe techniques used. The sketch of the shape of the samples is shown in Figure 1. The tensile samples contained a gauge section (called "notch" hereafter) working as stress concentrator within the specimen. The thickness of the $301 \mathrm{LN}$ steel plate was $1 \mathrm{~mm}$ and the "gauge section" was milled down to $0.1-0.2 \mathrm{~mm}$. The reference material was a carbon steel ("Q Panel", SAE 1008, ISO specification 3574, CR1-type) with a thickness of $0.8 \mathrm{~mm}$ and a hardness (on Rockwell B) of 50-65 Hb. The $301 \mathrm{LN}$ was investigated in the tempered and rolled condition meaning that substantial work hardening and straininduced martensitic phase were present. ${ }^{20}$ The mechanical properties were determined by tensile testing on a flat specimen with a testing speed of $0.0067 \mathrm{~s}^{-1}$ (see Table II).

Unless otherwise specified, the steel surface for SKP and LEIS measurements was grinded using silicon carbide paper down to $\mathrm{SiC}$ $\# 1000$, degreased in ethanol, rinsed in deionized water and stored in dry air. A constant load cell equipped with load sensor was used to apply tensile load in the range of 200-650 $\mathrm{MPa}^{20}$

Scanning kelvin probe.-SKP is often used for measuring the Volta potential difference with respect to any reference electrode or the electron work function $(\boldsymbol{e} \boldsymbol{w} \boldsymbol{f})$ with respect to the zero level in vacuum. ${ }^{22}$ The electrochemical potential of the electrons, $\alpha$, is defined as the work to remove one mole of electrons from the infinity (i.e. in vacuum) to the Fermi level inside the metallic phase and is

Table II. Mechanical properties of 301LN and SAE 1008, $R_{p 0.2}$ is proof stress, $R_{m}$ is ultimate tensile strength, $A_{g}$ elongation at maximum force and $A_{t}$ total elongation to fracture.

\begin{tabular}{ccccc} 
Material & $\mathrm{R}_{\mathrm{p} 0.2}[\mathrm{MPa}]$ & $\mathrm{R}_{\mathrm{m}}[\mathrm{MPa}]$ & $\mathrm{A}_{\mathrm{g}}[\%]$ & $\mathrm{A}_{\mathrm{t}}[\%]$ \\
\hline 301 LN & 534 & 846 & 35 & 45 \\
SAE 1008 & 285 & 340 & - & 25
\end{tabular}

given by Eq. 1 .

$$
\Phi \mathrm{N}_{\mathrm{A}}=-\alpha=-\mu_{e}-\mathrm{F} X_{w}
$$

where $\Phi$ is the $\boldsymbol{e w f}, \mu_{e}$ is the Fermi level of the electrons in the metal, the $X_{w}$ is potential drop across metal surface, $N_{\mathrm{A}}$ and $F$ are the Avogadro and the Faraday constants. ${ }^{23}$ Thus, the potential ( $\Phi / e, e$ being the elementary charge) has bulk and surface contributions. For a metal covered by an oxide film, the potential drop can be expressed as:

$$
X_{w}=\frac{\mu_{o x}-\mu_{e}}{e}+F_{b}+\beta_{o x / a i r}
$$

This equation shows that the contact potential difference between the metal and the oxide is proportional to the difference in Fermi levels of the electrons in the metal $\left(\mu_{e}\right)$ and in the oxide $\left(\mu_{\mathrm{ox}}\right) . F_{b}$ is the potential drop in the oxide, and $\beta_{\text {ox/air }}$ is a contribution accounting for the potential drop of adsorbed molecules on the oxide surface. For an iron oxide film, $\mu_{\mathrm{ox}}$ is governed by the ratio of activities $\left[\mathrm{Fe}^{3+}\right]$ $/\left[\mathrm{Fe}^{2+}\right]$ whereas for stainless film, both chromium and iron species have to be taken into account. ${ }^{24}$ In a corrosive environment, the SKP measures the potential corresponding to the corrosion potential. ${ }^{25}$ In dry air conditions, the measurement relates to the potential of steel in the passive state controlled by red-ox potential of the surface species. ${ }^{24,26}$ In addition, it was shown that the potential of stainless steel is influenced by the oxide film thickness, ${ }^{20}$ the potential being more positive for a thicker film. Thus, probe-working electrode Volta potential difference relates to electrochemical potential of the working electrode given relative to a reference electrode.

The SKP equipment (UBM Messtechnick) uses vibration capacitor principle to measure the surface distribution of the Volta potential. For measurements in situ under load, a constant load cell with fixed tensile sample was inserted in the SKP chamber. ${ }^{20}$ The experiments were performed in laboratory air at ambient temperature $22^{\circ} \mathrm{C}$ and at $50 \% \mathrm{RH}$. The reference electrode was a needle of a Ni-Cr alloy with a tip diameter of $100 \mu \mathrm{m}$ allowing a lateral resolution in the range of $100 \mu \mathrm{m}$. In a first step, a topography profile was measured. Then, the SKP scanning of the sample was performed with a constant probeto-sample distance $(50 \mu \mathrm{m})$ and a vibration amplitude of $20 \mu \mathrm{m}$ at a frequency of $2 \mathrm{kHz}$. In standard measurements, the data recording density was 16 points $/ \mathrm{mm}$ along the $\mathrm{X}$-axis and 4 points $/ \mathrm{mm}$ along the Y-axis. Before the measurements, the potential of the probe was calibrated with respect to a saturated $\mathrm{Cu} / \mathrm{CuSO}_{4}$ electrode. All SKP potentials are given versus the standard hydrogen electrode (SHE).

Local electrochemical impedance spectroscopy.-A potentiostat (Gamry, Reference 600) was used for pre-treating steel in an aqueous buffer electrolyte $0.075 \mathrm{M} \mathrm{Na}_{2} \mathrm{~B}_{4} \mathrm{O}_{7} 10 \mathrm{H}_{2} \mathrm{O} / 0.015 \mathrm{M} \mathrm{B}(\mathrm{OH})_{3}$ 

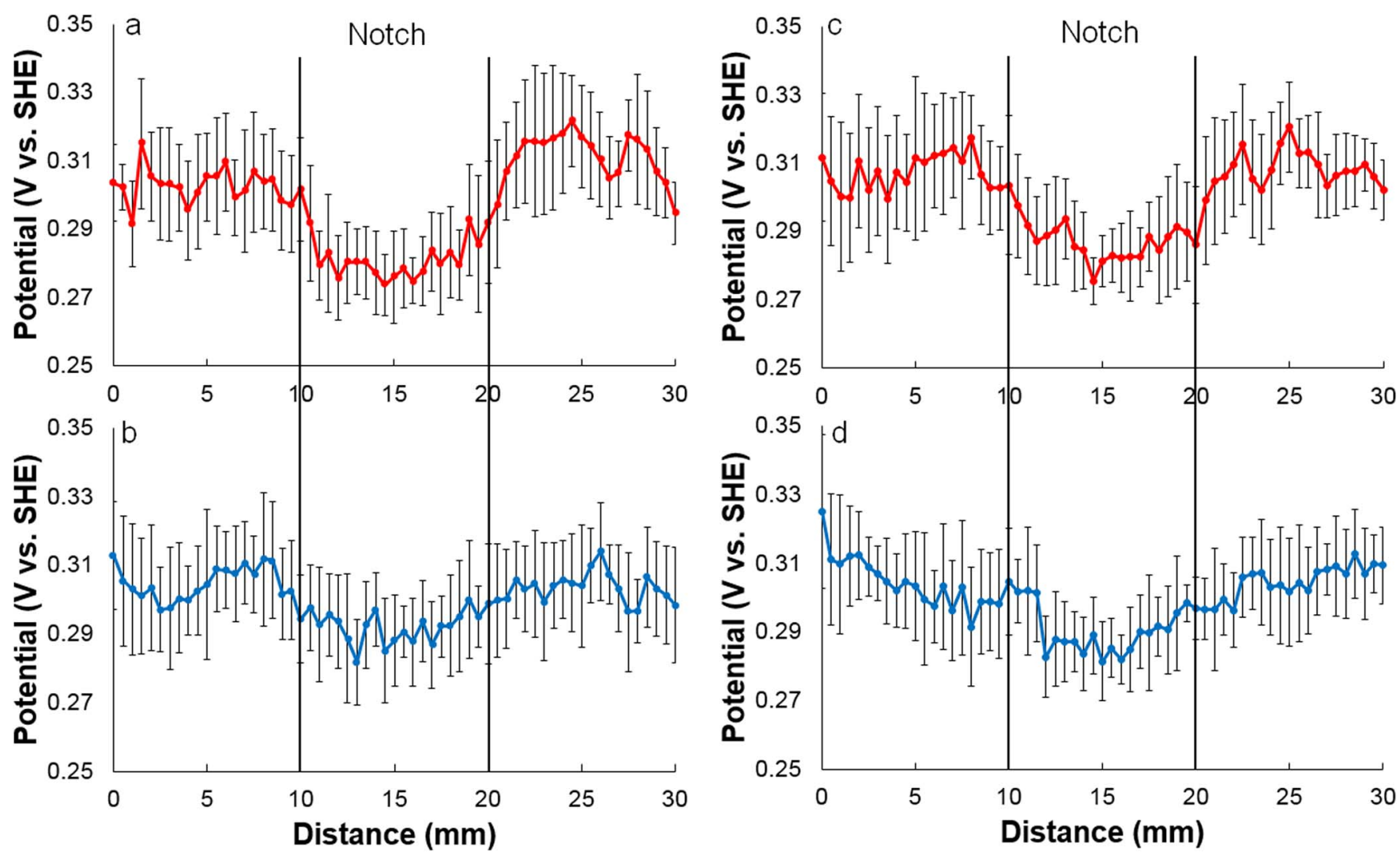

Figure 2. Averaged potential distribution with error bars across the notch for carbon steel electrode under the load $200 \mathrm{MPa}$ (a) and $260 \mathrm{MPa}$ (c) and in $24 \mathrm{~h}$ after unloading $200 \mathrm{MPa}$ (b) and $260 \mathrm{MPa}$ (d). The measurements were carried out in air at 50\% RH.

$(\mathrm{pH}=9.2)$. A 3-electrode cell was used including a Pt wire counterelectrode and $\mathrm{Ag} / \mathrm{AgCl}$ saturated electrode as a reference.

Local electrochemical Impedance Spectroscopy (LEIS) measurements were performed with a home-made setup in a borate electrolyte with an AC perturbation of $25 \mathrm{mV}$ peak-to-peak, the potential of the sample was referred to SHE. LEIS mapping was performed at a constant frequency of $5 \mathrm{kHz}$. The local probe consisted of a $\mathrm{Ag} / \mathrm{AgCl}$ bi-microelectrode of $50 \mu \mathrm{m}$ in radius used as local potential sensors. ${ }^{27}$ The local potential difference measured was amplified using a homemade differential amplifier and converted to a local current density using ohm's law. ${ }^{28}$ It is thus used to measure the local impedance using a multichannel frequency response analyzer, allowing the simultaneous measurement of both local and global electrochemical impedances. $^{29}$ The $301 \mathrm{LN}$ samples were pre-strained to a $10 \%$ tensile strain. Before the LEIS experiments, the air formed oxide film was reduced at $-1.2 \mathrm{~V} / \mathrm{SHE}$ for $10 \mathrm{~min}$. The mapping was performed at fixed potentials at -0.1 and $+0.4 \mathrm{~V} / \mathrm{SHE}$. In addition, LEIS was measured for $301 \mathrm{LN}$ steel and carbon steel at the center of the notch as function of the load.

Surface analyses by XPS, AFM and light topography profiling.The oxide film on deformed steel surface was characterized by X-ray Photoelectron Spectroscopy (XPS, Thermo VG Thetaprobe). The 301 LN steel oxide layer composition was analyzed using a two-layer oxide film model that consisted of an iron oxide $\left(\mathrm{Fe}_{2} \mathrm{O}_{3}\right)$ outer layer and a chromium oxide $\left(\mathrm{Cr}_{2} \mathrm{O}_{3}\right)$ interlayer. ${ }^{30}$ The notch area contained the residual stress due to previous yielding and the location without the stress (i.e. outside the notch area) were analyzed.

The influence of plastic deformation on surface topography and roughness was studied by Atomic Force Microscopy (AFM, Bruker nanoscope multimode 8) using the tapping mode (cantilever frequency of $354.83 \mathrm{kHz}$ ). The probe (RTESP MPP-11100) showed a typical tip curvature between 5 and $10 \mathrm{~nm}$.
The evolution of the surface roughness after straining or sample grinding was studied with a profilometer (Veeco, WYKO Surface light Profiler).

\section{Results}

Influence of the strain on the Volta potential of carbon steel.The Volta potential difference was measured on tensile specimens under load to reach elastic stresses of 200 and $250 \mathrm{MPa}$ in the work area. The initial potential for a non-deformed surface was uniform and close to $300-330 \mathrm{mV}$, whereas when the measurements were performed under the applied load, the potential in the notch area decreased by $21+/-20 \mathrm{mV}(200 \mathrm{MPa})$ and $28+/-20 \mathrm{mV}(250$ $\mathrm{MPa}$ ) compared with surrounding surfaces (Figures 2a, 2c). The data calculated by averaging the potential above and around the notch areas and contain confidence interval (error bars). Then, the sample was unloaded and the measurement was repeated after $24 \mathrm{~h}$ of exposure after unloading (Figure 2, curves b, d). The scattering of the potential increased and the potential drop in the notch was lower. Thus, elastic deformation only slightly decreased the Volta potential of the carbon steel. This is in agreement with literature data for other materials, e.g. the elastic stress can decrease or increase potential of $\mathrm{Al}, \mathrm{Cu}$ or steel for 5-10 mV..$^{20,31-34}$

Figure 3 a shows the distribution of the potential across a carbon steel sample under the load of $310 \mathrm{MPa}$. This is higher than the yield strength $(285 \mathrm{MPa})$ and the measurement of elongation gives the plastic strain close to $10 \%$. SKP showed the area of low potential of $200 \mathrm{mV}$ in the notch relative to the surrounding surface. Another sample was strained to $15 \%$ (330 MPa) and the potential drop in the notch area compared with the surrounding was about $100-150 \mathrm{mV}$ (Figure 3b). Logically, it can be expected that increase of the strain will proportionally decrease the potential. However, the experimental data (Figures 3a, 3b) showed that the dependence is more complex. 
a

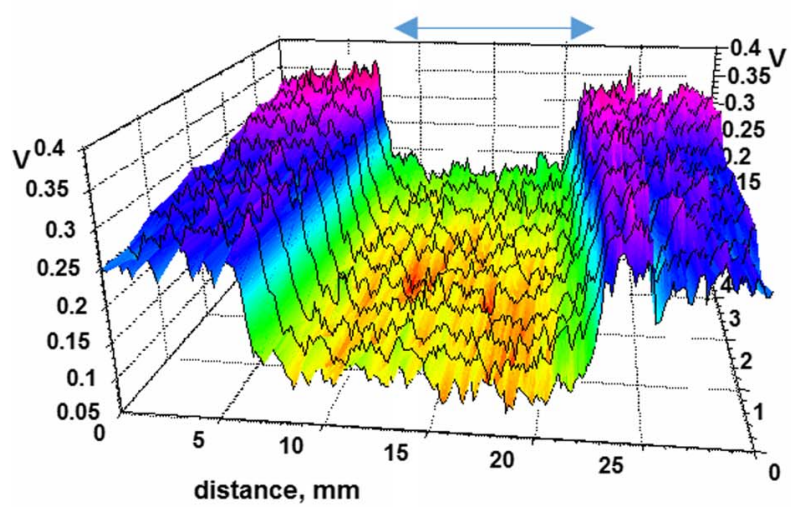

notch

b

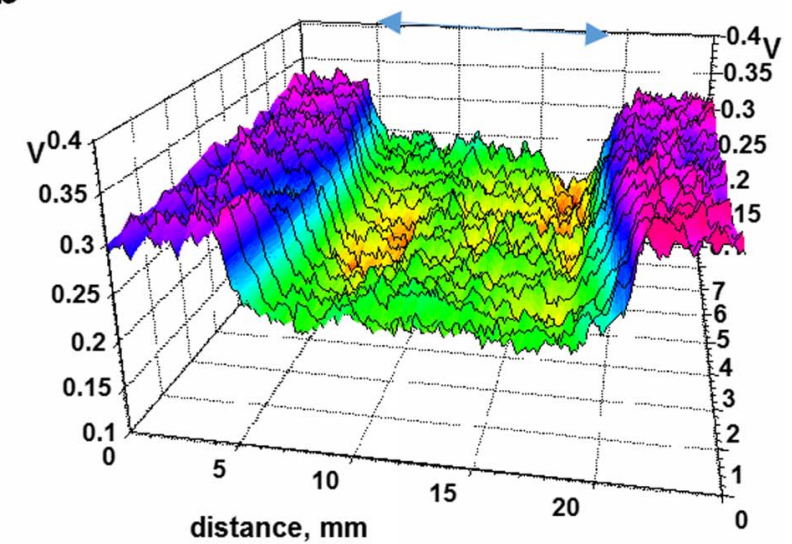

C

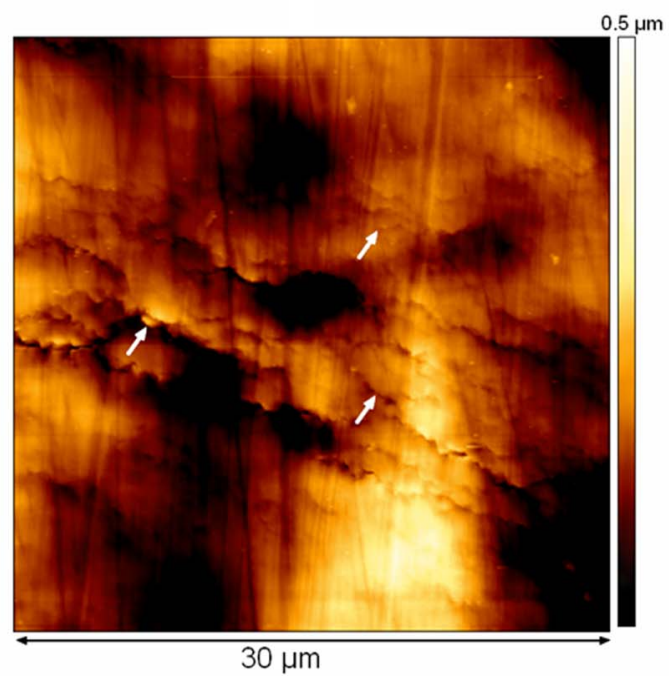

Figure 3. Potential maps of the carbon steel sample in the area of the notch under the load. The measurements were done in air at $50 \% \mathrm{RH}$ under (a) 310 $\mathrm{MPa}$ and (b) $330 \mathrm{MPa}$. (c) AFM picture of the strained area of specimen with $10 \%$ plastic strain. White arrows indicate some dislocation slip bands.

The potential can be a function of the thickness of oxide layer and the rate of the loading that can influence on the dislocations pattern (e.g. formation of the cells with high plastic strain ${ }^{11,13}$ ). However, these parameters were not controlled in this study. The formation of slip bands in the strained area is shown by AFM topography in Figure 3c.

The sample with $10 \%$ tensile strain was unloaded and the measurements were repeated after $24 \mathrm{~h}$ under rest conditions (Figure 4A).
Compared with potential under load, the potential increased from 130 to $270 \mathrm{mV}$ over most of the surface of the notch that can be related to passivation of the pre-strained surface. In general, SKP measurements were carried out in laboratory air. Oxygen adsorption on the oxide surface can create a layer of ordered dipoles that can influence on the potential (Eq. 2). To evaluate the possible adsorption effect, some measurements were repeated in a dry nitrogen atmosphere. Potential profiles in the notch area before and after plastic strain $10 \%$ elongation are shown in Figure 4A. A potential drop due to residual stress concentrated in the gauge section after plastic deformation can be observed in atmosphere of air $(70+/-20 \mathrm{mV})$ or nitrogen $(110+/-20 \mathrm{mV})$.

Grazing angle XPS was used to analyze the influence of the strain on the condition of passive film. The reference was defined as the nondeformed regions outside of the work area on the same specimen. The results showed that prior tensile plastic deformation increased slightly the thickness of iron oxide layer, from about $2.2 \mathrm{~nm}$ to about $2.7 \mathrm{~nm}$. Moreover, the analysis of the O1s peak showed an increase of the contribution of $\mathrm{OH}^{-}$group with the plastic deformation (see Figure 4B). It is thus concluded that the passive film of the strained area was more defective and had an increased content of iron hydroxides.

The potential distribution was measured 1 month after unloading. Long-time exposure in a dry air atmosphere led to an increase of the Volta potential to a level $50-80 \mathrm{mV}$ more positive relative to the area surrounding the notch. A possible explanation is that the relaxation of the pre-stressed oxide film resulted in an increase of the oxide film thickness, which is in line with XPS measurements. On the other hand, healing of the defects in the freshly formed oxide by oxidation of $\mathrm{Fe}^{2+}$ to $\mathrm{Fe}^{3+}$ may have also played a role and increased the potential of the gauge section during ageing.

LEIS measurements of the strained carbon steel surface.-The effect of the stress was studied by local electrochemical impedance spectroscopy in boric/borate aqueous electrolyte. It is possible to compare the impedance for the strained and non-strained areas. The carbon steel sample was strained using the constant load cell and the stress was controlled by a load sensor. The local impedance was monitored by performing a measurement at a single location at the center of notch simultaneously with the global impedance, which corresponds to an averaged value over the whole exposed surface to the electrolyte. Figure 5 shows that the load (300 MPa) increased the local capacitance from 2 to $3.4 \mu \mathrm{F} / \mathrm{cm}^{2}$. In first approximation, this increase of capacitance can be seen as a thinning of the passive film when increasing the mechanical stress. A similar effect can be the result of increasing the real surface of the working electrode, for instance due to increasing of the surface roughness.

The yield stress is $285 \mathrm{MPa}$, as shown in Table II, and the tensile strain increases the capacitance during both the elastic and plastic deformation. Conversely, to the local capacitance, the global measurement shows a constant value of the mean capacitance whatever the mechanical load. Thus, the local variation of the impedance due to the strength has only a light contribution on the global EIS response indicating that the local variation of the capacitance is localized above the notch area only, and can be monitored only with the help of a spatially resolved techniques.

The open circuit potential (OCP), which was monitored using an $\mathrm{Ag} / \mathrm{AgCl}$ reference electrode, decreased due to straining from -0.12 to $-0.38 \mathrm{~V} / \mathrm{SHE}$. This effect was observed only after reaching the yield stress. A negative shift of the OCP can be related to the formation of defects or to the decrease of the oxide film thickness due to local breakdown in the film. Interestingly, the OCP value, which is a global measurement, appears to be sensitive to local modifications of the oxide film.

The sample was unloaded and LEIS was monitored during exposure in the electrolyte. After $12 \mathrm{~h}$ of exposure, the OCP increased by $40 \mathrm{mV}$ to reach $-0.34 \mathrm{~V} / \mathrm{SHE}$ and the local capacitance decreased from 3.4 to $2.5 \mu \mathrm{F} / \mathrm{cm}^{2}$. Thus, defects in the oxide film repair and in absence of loading the surface can partially re-passivate. The LEIS data in electrolyte are in line with SKP measurements in air 

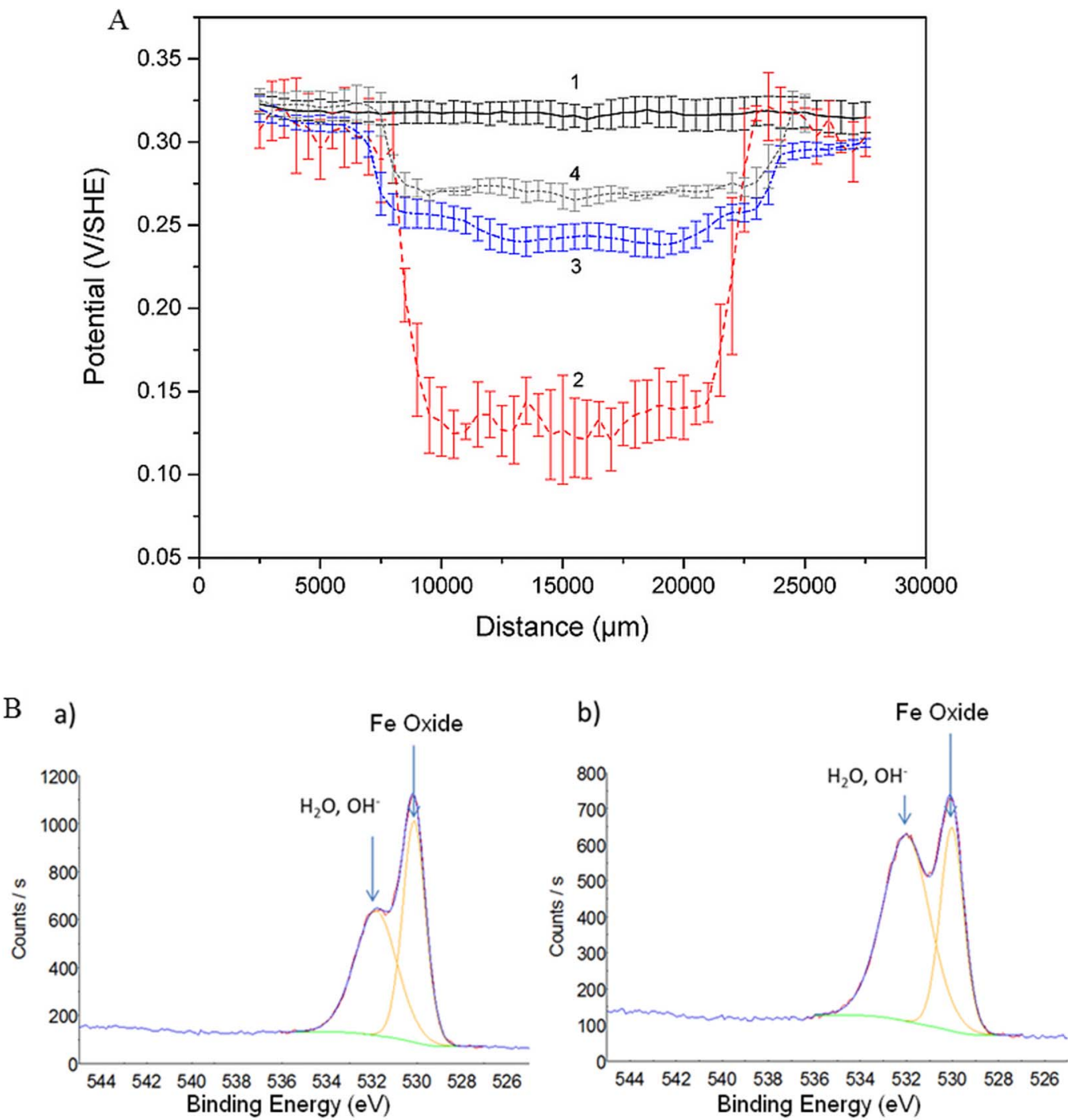

Figure 4. A- averaged potential distribution with error bars across the notch area. 1-potential of initial surface, 2-potential of the surface under the load (310 MPa); 3,4 -potential of the unloaded surface measured in dry air $5 \% \mathrm{RH}(4)$ and in dry nitrogen $5 \% \mathrm{RH}(3)$ atmospheres. B- $\mathrm{XPS}^{-}$spectrum, $\mathrm{OH}^{-} / \mathrm{H}_{2} \mathrm{O}$ and iron oxide contribution on the O1s peak (a) reference unstrained area and (b) plastic strained area.

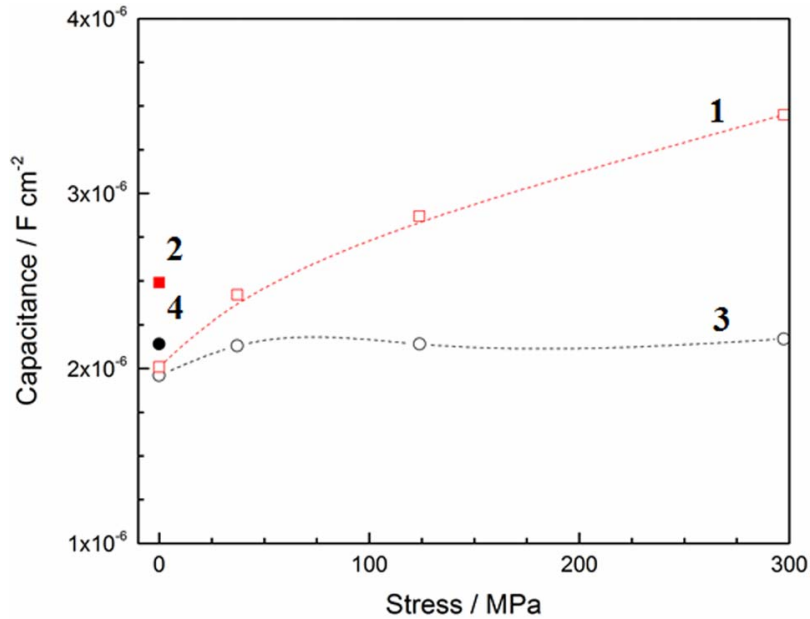

Figure 5. Influence of the mechanical load on the local $(1,2)$ and global $(3,4)$ capacitances of the carbon steel in borate electrolyte. The measurements 2 and 4 were performed after unloading.
(Figure 4A). The potential of the notch area increased and the capacitance decreased after unloading. LEIS and SKP show that the pre-strained carbon steel surface was not stable. XPS measurements conducted a month after straining showed formation of mixed oxidehydroxide film (Figure 4B).

SKP and XPS measurements of austenitic 301 LN steel.-The sample of stainless steel $301 \mathrm{LN}$ with reduced thickness in the gauge section was loaded up to $650 \mathrm{MPa}$. This stress was higher than the tensile strength (Table II) and the Volta potential in the area of the notch decreased by $250 \mathrm{mV}$. Figure 6 shows the potential distribution across the tensile specimen under the load and after unloading. The data across the profile were averaged and the error bars are shown in the figure. The length measurement confirmed a notch elongation of about $10 \%$. The sample was unloaded and the potential distribution was measured in $24 \mathrm{~h}$ after unloading (Figure 6, curve 2). The potential in the area of notch was decreased by the plastic strain compared with areas outside the notch, and it is in agreement with the potential variations for $301 \mathrm{LN}$ stainless steel ${ }^{20}$ and $\boldsymbol{e w f}$ for duplex stainless steel. ${ }^{34}$ Visual observation and AFM topography show 


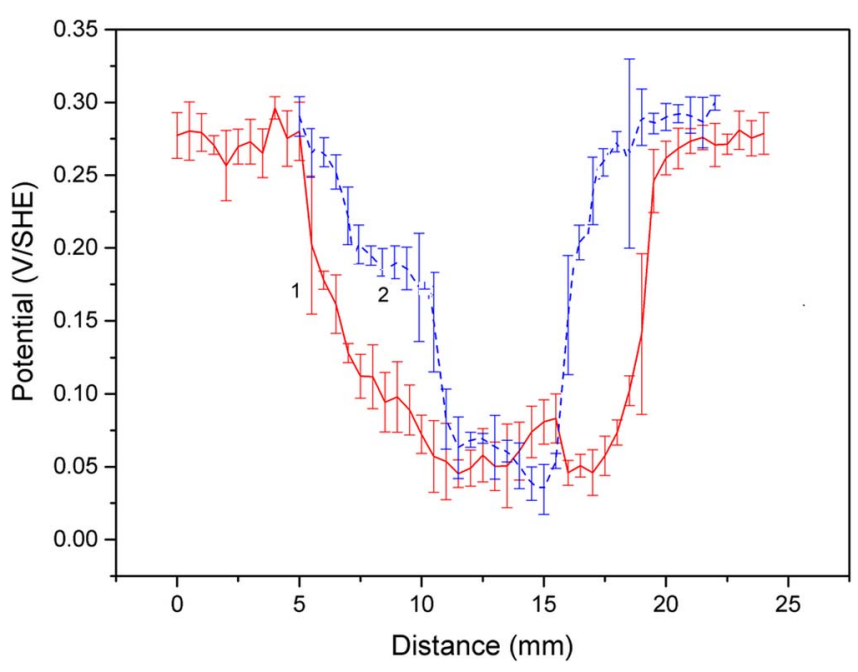

Figure 6. Averaged potential distribution with error bars across gauge section of $301 \mathrm{LN}$ steel sample under the load (1) and in load- free conditions (2). The measurements were carried out in air at $50 \% \mathrm{RH}$.

a
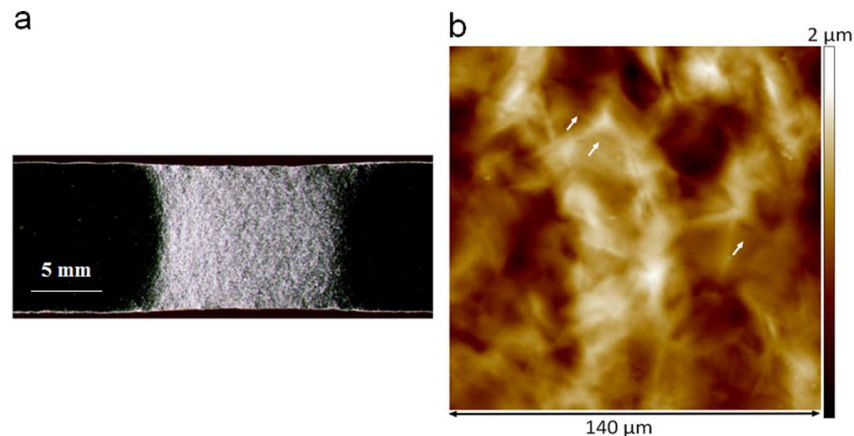

Figure 7. Photograph of the sample (a) and AFM topography of the strained area (b). The sample was loaded at $650 \mathrm{MPa}$ corresponding to $10 \%$ plastic strain. Some slip bands are indicated by white arrows.

the plastic strain, and slip bands, in the area of the residual stress (Figures 7a, 7b).

The thickness of the oxide film on $301 \mathrm{LN}$ influences the potential ${ }^{20}$ the thinner the oxide layer, the more negative the potential. In addition, the composition and oxidation state can also influence the potential drop across the oxide film. Thus, grazing angle XPS was used to analyze the influence of previously applied strain on the properties of surface oxide (Figure 8). The reference spectrum was obtained above the non-deformed regions, i.e. on the same specimen but outside of the notch domain. The results showed that tensile

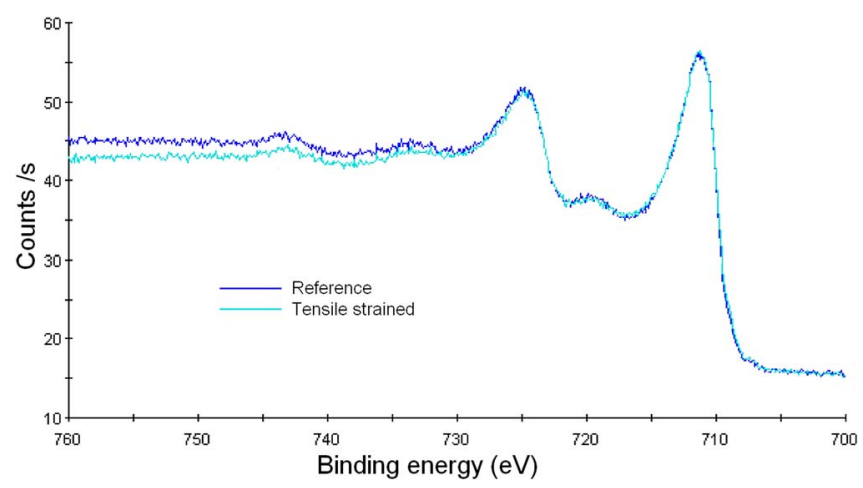

Figure 8. XPS of the Fe2p envelope in unloaded (reference), tensile strained specimen $301 \mathrm{LN}$ steel. Potential distribution is shown at Figure 6.

\section{Table III. Thickness of the oxide film (nm) calculated from XPS} spectra after tensile test. Ref. - reference point for sample without residual stress.

\begin{tabular}{ccc}
$301 \mathrm{LN}$ & $\alpha \mathrm{Fe}_{2} \mathrm{O}_{3}$ & $\mathrm{Cr}_{2} \mathrm{O}_{3}$ \\
\hline Ref. & 4.5 & 1.5 \\
Tensile & 4.8 & 1.1
\end{tabular}

plastic strain decreased only slightly the thickness of chromium oxide film and increased slightly the thickness of the iron oxide layer (Table III). Moreover, when the strain was applied in the air atmosphere, no modification of the $\left[\mathrm{Fe}^{3+}\right] /\left[\mathrm{Fe}^{2+}\right]$ ratio was found (Figure 8). It is important to note that XPS measurements were carried about 1 month after the sample straining. During exposure in dry air, a slow potential increase for the area with residual stress was observed. During this time, the relaxation of the surface oxide at the pre-strained locations can take place.

Comparing the influence of elastic and plastic deformation on the potential for carbon and stainless steels, it is possible to point out that yielding decreases the potential. The main effect of the yielding is the formation of dislocations that can influence the properties of the surface of steel electrodes. Unloading of the samples increases the potential for both steels. However, for stainless steel this process is slower than for carbon steel. A possible explanation is that on carbon steel surface the defects in the oxide film are repaired due to contact with air oxygen. Stainless steel is more stable to oxidation by air and thickening of the oxide in defects is a relatively slow process.

Influence of the surface roughness on the volta potential.- - It was assumed ${ }^{31-34}$ that the formation of dislocations can change the potential drop across the metal/air interface due to variation in the atomic density and accordingly to the interfacial dipole moment (Eq. 1), resulting in a decrease of the $\boldsymbol{e} \boldsymbol{w} \boldsymbol{f}$ at locations of peaks at the rough surface. On the other hand, semiconducting oxide film covered the steel surface. Variation of the atomic density can differently change the surface states in the oxide and $\boldsymbol{e w f} \boldsymbol{f}^{35}$ Thus, the effect of the surface roughness due to plastic deformation on the potential had to be studied.

The surface topography was measured for previously strained to $10 \%$ elongation carbon steel sample inside and outside of the notch in rectangles of $740 \times 440 \mu \mathrm{m}^{2}$. A 4-fold average roughness increase from $110 \mathrm{~nm}$ to $466 \mathrm{~nm}$ due to plastic strain was found, whereas it reached a 7-fold factor (from $92 \mathrm{~nm}$ to $690 \mathrm{~nm}$ ) for stainless steel sample under the same experimental conditions.

To mimic the effect of the roughness, the samples were ground using $\mathrm{SiC}$ emery paper of different grits. Initially, the $301 \mathrm{LN}$ steel surface was ground using $\mathrm{SiC \# 4000} \mathrm{paper} \mathrm{to} \mathrm{a} \mathrm{low} \mathrm{roughness} \mathrm{factor}$ $(31 \mathrm{~nm})$. Then, a part of the treated surface was ground with SiC\#80 paper creating an average roughness of $589 \mathrm{~nm}$, that is, a roughness close to that of $301 \mathrm{LN}$ steel after yielding. The stabilization of the oxide-film was achieved by exposing the sample for 3 days in dry air. It is noteworthy that no significant modifications of the thickness and the elements distribution occurred in the oxide film for $301 \mathrm{LN}$ steel surface after grinding with different roughness. ${ }^{20}$ Figure 9 shows the potential distribution across the $301 \mathrm{LN}$ steel surface with high (left hand side of the cartography) and low (right hand side of the cartography) roughness. Interestingly, the area with the lowest roughness showed a $30 \mathrm{mV}$ higher potential relatively the area with a high roughness.

Similar experiments were performed for carbon steel for which the smooth surface showed only an increase of $10 \mathrm{mV}$ of the Volta potential when compared to rough surface. Thus, the effect of the roughness on the potential was much lower compared with effect of the yielding. It is probable that the difference in Volta potentials (Figure 9) is related to residual stress that originates from the grinding. ${ }^{16,36}$ On the other hand, measurements of capacitance showed that rougher steel surface may lead to higher disordering of the surface oxide, which can also change the electronic properties of the film. ${ }^{37}$ 
high

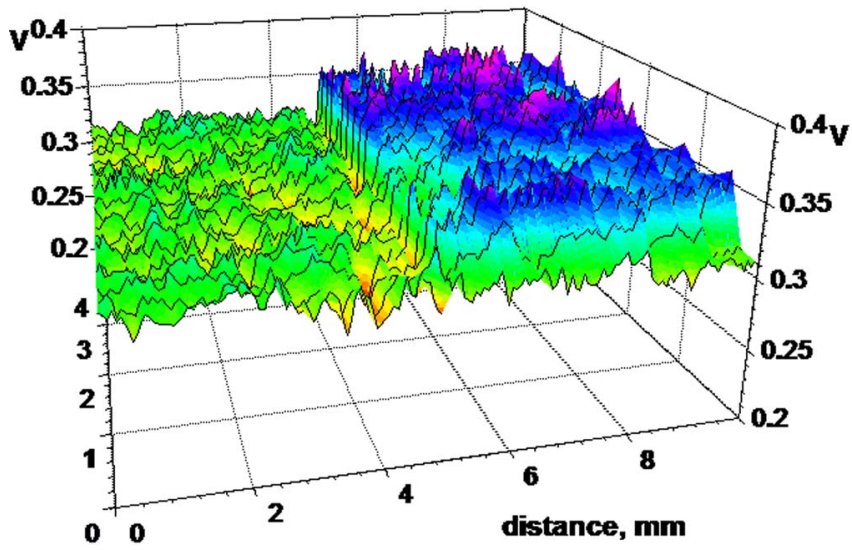

Figure 9. Potential profile for $301 \mathrm{LN}$ steel surface with different roughness $31 \mathrm{~nm}$ (low) and $589 \mathrm{~nm}$ (high). The measurements were carried out in air at $50 \% \mathrm{RH}$.

SKP and LEIS study of strained zones of $301 \mathrm{LN}$ steel.-It is also important to evaluate the effect of straining in the presence of the electrolyte. The area of the notch and around the notch was exposed to a borate solution in a conventional electrochemical cell. The air formed oxide film was reduced at $-1.2 \mathrm{~V}$ (SHE) for $10 \mathrm{~min}$ and the steel sample was polarized at fixed potentials for $1 \mathrm{~h}$. The sample of 301 steel was then strained to $10 \%$ of elongation in the electrolyte under polarization. The SKP measurements were performed in air after rinsing the unloaded sample in deionized water and drying in a stream of dry air. The potential profile (Figure 10a) shows the potential distribution across the notch for the sample polarized at $-0.1 \mathrm{~V} / \mathrm{SHE}$. This potential is close to the OCP measured for of the steel in borate electrolyte. The profile shows low potential areas in the middle part related to the notch where the potential drop reached about $300 \mathrm{mV}$.

Figure 10b shows the potential distribution for steel after an anodic polarization of $0.4 \mathrm{~V} / \mathrm{SHE}$. Some locations inside the notch exhibited increased Volta potential and some of them show very low potentials. The potential contrast between strained and non-strained area increased to $500 \mathrm{mV}$. Thus SKP visualizes the areas with residual stress which have low ability to passivate the surface.

The LEIS was applied using the same setup. The measurements of the capacitance were performed in situ during elastic deformation in the range $0-125 \mathrm{MPa}$ in borate electrolyte. The LEIS data show that stress increased the capacitance at the center of the notch from 2.3 to $2.410^{-6} \mathrm{~F} / \mathrm{cm}^{2}$ (data are not shown). Thus, elastic tensile strain shows only minor influence on the properties of the steel surface.

The same experiment was performed on $301 \mathrm{LN}$ steel with a prestrained sample used for SKP measurements corresponding to $10 \%$ of elongation (Figure 10). Before LEIS measurements the oxide film was reduced at $-1.2 \mathrm{~V}$ (SHE) for $10 \mathrm{~min}$. Figure 11 shows the distribution of the capacitance across the non-strained and strained areas. In that case, the deformation results in a significant increase of the capacity from about 2.3 to $4.510^{-6} \mathrm{~F} / \mathrm{cm}^{2}$ above the deformed area with a well-defined transition zone.

\section{Discussion}

SKP measures the Volta potential $(\Phi / e)$ in air close to the metal surface. On an absolute potential scale, the potential of the metal covered by semiconducting oxide film can be expressed as: ${ }^{24,38}$

$$
\frac{\Phi}{e}=-\frac{\mu_{e}^{M}}{e}+\Delta \mathrm{\chi}_{o x}+\Delta \mathrm{\chi}_{a i r}=-\frac{\mu_{e}^{M}}{e}+\frac{q}{C_{o x}}+\frac{q}{C_{a i r}}
$$

Where $\mu_{\mathrm{e}}{ }^{\mathrm{M}}$ is the chemical potential of the electron in the metal bulk, $\Delta \chi_{\text {ox }}$ - the potential drop in the oxide film (metal-oxide inter- a notch

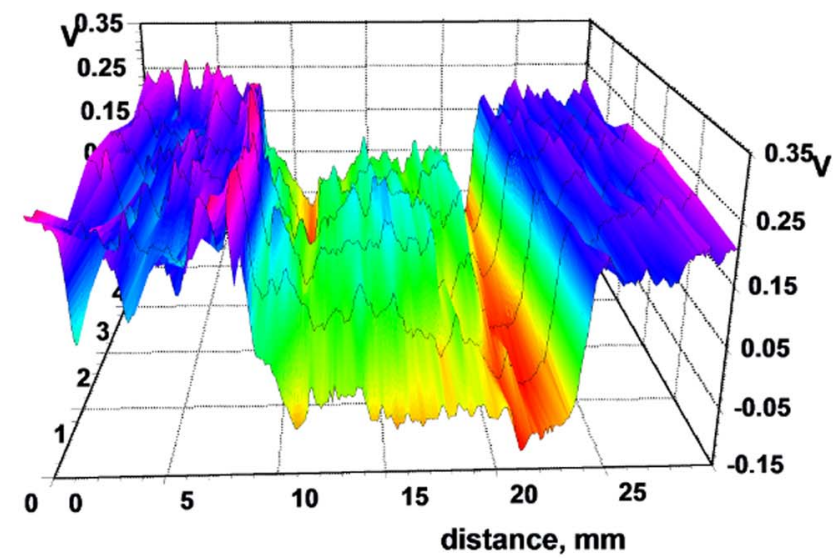

b

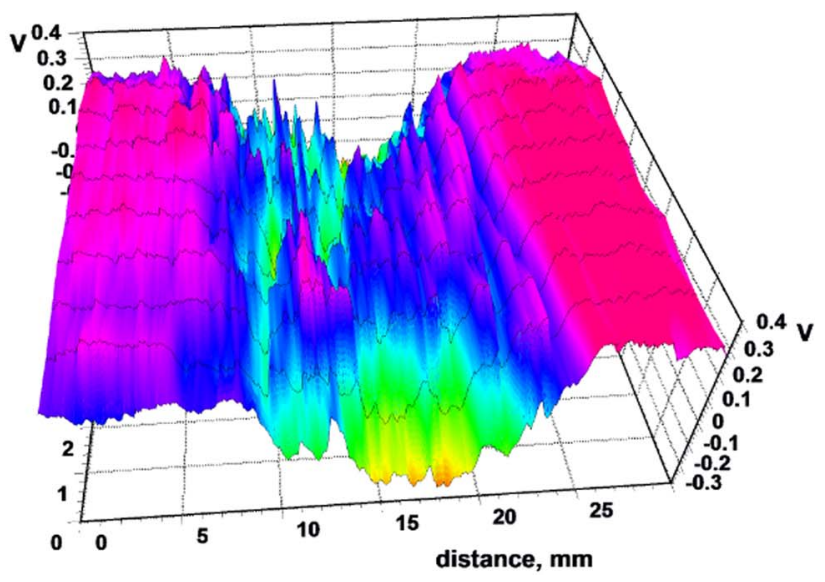

Figure 10. SKP profiles of $301 \mathrm{LN}$ steel, after yielding $10 \%$ in borate electrolyte. a- $1 \mathrm{~h}$ polarization at $-0.1 \mathrm{~V}(\mathrm{SHE})$. b- $1 \mathrm{~h}$ polarization at $0.4 \mathrm{~V}(\mathrm{SHE})$. The measurements were carried out in air at $50 \% \mathrm{RH}$

face) and $\Delta \chi_{\text {air }}$ - the potential drop in the air gap. Eq. 3 shows the relationship between the measured potential and the corresponding capacitances $\left(C_{\mathrm{ox}}, C_{\text {air }}\right)$ and the charges stored at this interface $(q)$. Due to electroneutrality, the charges of adsorbed species (e.g. $\mathrm{O}_{2}{ }^{-}$) are compensated by the same amount of charges in the oxide (e.g. holes) resulting in band bending of both electronic and valence bands in the oxide. The capacitance of the oxide film is reciprocal to the potential drop. Thus, SKP and EIS (or LEIS) measurements are interrelated and can be used in a complementary fashion to evaluate the effect of the mechanical stress on the properties of the steel surface.

According to fundamental definitions, ${ }^{23,38}$ the electrode potential is defined by the energy level of the electron or metal ion. The steel electrode has both electronic and ionic energy levels and the ionic and electronic potentials can be correlated. Thus, the potential of the metal can be represented in terms the real free energy of metal ion that is measured by the corresponding reference electrode in the electrolyte. The same potential corresponds to the real free energy of the electron at the Fermi level of the metal and can be measured using SKP. Thus, the mass transfer between metal and environment correlates with electron transfer and the Volta potential measured by SKP is related to electrochemical potential of the steel (Eq. 1).

The SKP study showed that tensile plastic deformation of austenitic and carbon steels decreased the electrode potential. The stress can influence the chemical potential of the electron in the metal $\left(\mu_{\mathrm{e}}^{\mathrm{M}} / \mathrm{e}\right)$ or the potential drop across the metal/oxide/air interface (Eqs. $1 \&$ $3)$. The calculation within the self-consisting Kohn-Sham method for elastically deformed metal crystals showed that tensile strain de- 

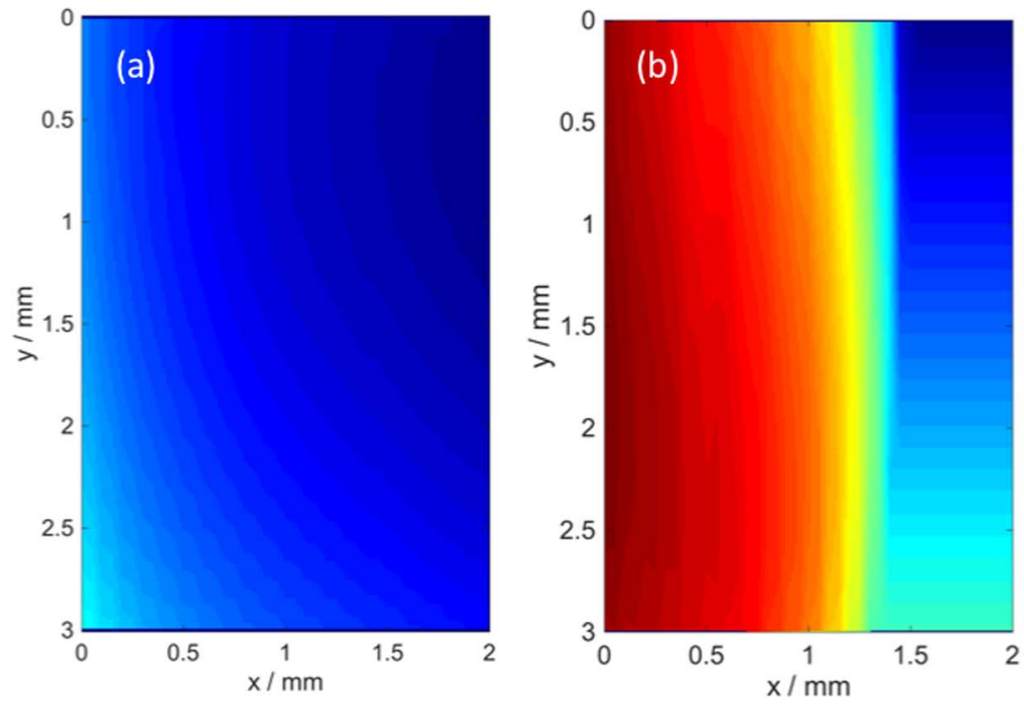

\section{Capacitance}

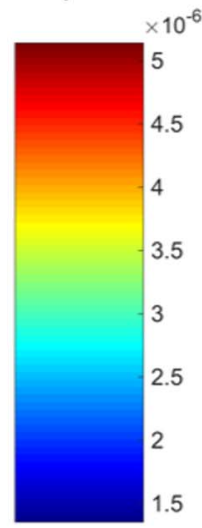

1.5

Figure 11. LEIS maps for two parts of the $301 \mathrm{LN}$ steel sample scanned after yielding 10\%. a- outside the notch, b-the area of the notch. The measurements were carried out at $0.4 \mathrm{~V}$ vs. SHE in borate electrolyte.

creased the density of the atoms packing and concentration of the electrons that can decrease $\boldsymbol{e} \boldsymbol{w} \boldsymbol{f}$ in the range $30-40 \mathrm{mV}$ for $\mathrm{Al}$ and $\mathrm{Cu}$ (111 and 100 planes). ${ }^{39}$ The stress can influence the potential drop across metal/vacuum interface due to the change of the distance between surface atoms, while the change of the chemical potential of the electron (Fermi energy) in the metal bulk was negligible. Thus, the properties of the material bulk were not altered by the stress, which is in agreement with calorimetry measurements and thermodynamic definition of Hoar. ${ }^{9}$ It can be assumed that the stress mainly influenced the potential drop across metal/oxide and oxide air/interfaces. The potential mainly decreased when the specimen was loaded over the yield strength, leading to the formation of dislocations. Plastic strain in the range of $10-15 \%$ decreased the potential of $200-300 \mathrm{mV}$ for $301 \mathrm{LN}$ steel and around $200 \mathrm{mV}$ for the carbon steel. Similar effects were found for the yielding of $\mathrm{Cu}$ and $\mathrm{Al}^{31-33}$ The further increase of strain showed only small influence on the potential. Application of strain to 301 LN steel sample higher than 20-30\% (data not shown) did not lead to extra drop in potential. Thus, it is possible to point out that, defects in the oxide film and locations with thin oxide film were created by tensile plastic stress through dislocations and emerging slip bands. The potential drop across the passive oxide film was decreased, creating areas of high corrosion activity.

The degradation of the passive oxide film due to the residual stress after tensile deformation was also shown by LEIS for the $301 \mathrm{LN}$ steel. SKP and LEIS have near the same level of spatial resolution. Higher capacitance was obtained on surface with emerged dislocations comparing with the unstrained reference. The strained area with increased capacitance (Figure 11) corresponded to area with decreased of potential measured by SKP (Figure 10). Thus, the potential drop in the oxide film is reciprocal to film capacitance (Eq. 3).

The effect of dislocations on properties of passive films is not well defined. It may be induced by slip lines or pile-ups of the dislocations. The yielding increases the surface roughness to factors of 4 (carbon steel) and 7 (stainless steel). Increase of the real metal surface relates to decreasing the density of the material. New surfaces can result in a lowering of the oxide thickness that can play an important role in the initiation of stress corrosion cracking of stainless steels. ${ }^{40,41}$ It is thus possible that areas with low oxide thickness are created under stress due to the oxide film rupture or emerging of the slip bands. ${ }^{42}$ It is gradually different from the roughness created by the grinding (Figure 9). In the last case, the compressive stress can be developed and no significant decrease of the material density takes place. The schematic of the strained surface is given in Figure 12.
For practical case, it is important to compare data obtained in air and in electrolyte. In the electrolyte, a cathodic polarization for the reduction of the air formed oxide was applied. After electrochemical treatment the notch obtained lower potentials comparing with strained in the air. It can be due to the concomitent effect of the hydrogenation and stress on the steel. Thus, it is in line with observation that both the stress and hydrogen entry decreases OCP. ${ }^{43}$

A similar effect of cold work or straining on the capacitance of the oxide film was observed in few studies. ${ }^{15-17,40,41,44}$ In these works, the effect of mechanical work was explained by increasing the densities of the donors or acceptors that changes the properties of the semiconducting oxide film. On the other hand, it was observed that stress has only a small influence on the flatband potential of the oxide films. The results of this work show that plastic stress increases the capacitance and decreases the potential drop in the oxide film. Emerging of dislocations create a defective oxide film that is prone to anodic dissolution in form of pitting corrosion or stress corrosion cracking.

\section{Conclusions}

1. It was demonstrated that SKP and LEIS are local electrochemical techniques that are able to visualize the distribution of the residual stress with similar spatial resolution.

The plastic tensile deformation decreased the electrochemical potential of carbon and austenitic steels measured in air. The strain increased the capacitance of the steels in the borate aqueous electrolyte.

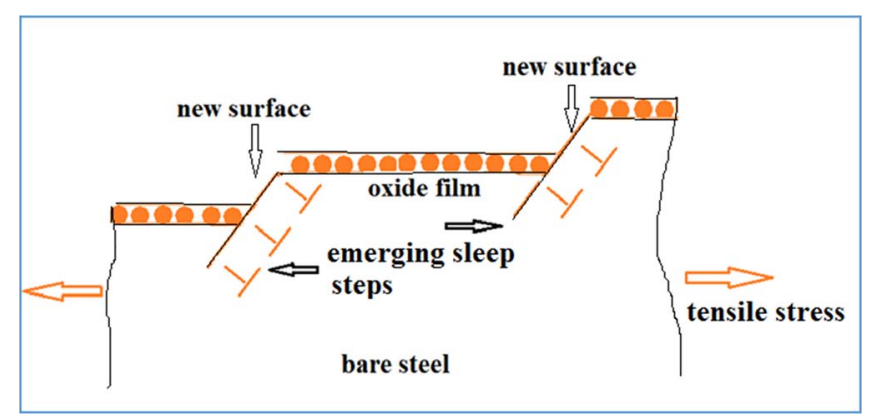

Figure 12. Sketch of the steel surface created by a tensile plastic deformation. 
2. It was shown that plastic strain creates dislocations and emerging the dislocations that creates defects in the oxide film. The dislocation pile-ups and sliding lines showed low electrochemical potential and they are prone to local corrosion.

3. Local probe techniques - SKP in air and LEIS in the aqueous electrolyte - demonstrated that residual stress decreased the ability of the steel to passivate the surface either in the air or in the electrolyte.

\section{Acknowledgments}

The authors thank Vincent BARNIER (École des Mines de SaintÉtienne, France) and Philippe ELIES (Brest University, France) for XPS and AFM measurements.

\section{References}

1. A. Barbucci, G. Cerisola, and P. L. Cabot, J. Electrochem. Soc. 149, 534 (2002)

2. R. W. Staehle, in: "Stress Corrosion Cracking and Hydrogen Embrittlement of Ironbased Alloys", R. W. Staehle, J. Hochmann, R. D. McCright, and J. E. Slater (Eds.), p.180, NACE-5, NACE, Houston, TX, 1977.

3. B. D. Craig, Fundamentals Aspects of Corrosion Films in Corrosion Science, Plenum Press, New York, 1991.

4. T. Nakayama and M. Takano, Corrosion, 42, 10 (1986)

5. F. P. Ford, Corrosion NACE, 52, 375 (1996).

6. P. L. Andersen and F. P. Ford, Int. J. Pres. Ves. \& Piping, 59, 61 (1994).

7. A. R. Despic, R. G. Raicheff, and J. O'M Bockris, The Journal of Chemical Physics, 48, 926 (1968).

8. E. M. Gutman, G. Solovioff, and D. Eliezer, Corrosion Sci., 38, 1141 (1996).

9. T. P. Hoar, in Proceedings of the conference "Fundamentals of Stress corrosion Cracking, p.98, NACE TX, (1969).

10. H. H. Uhligh, in: Physical Metallurgy of Stress Corrosion Fracture, T. Rhodin (Ed.) p. 1, Interscience, New York, (1959).

11. M. Sahal, J. Creus, R. Sabot, and X. Feaugas, Acta Materialia, 54, 2157 (2006)

12. K. Saito and J. Kuniya, Corrosion Sci., 43, 1751 (2001).

13. D. Large, R. Sabot, and X. Feaugas, Electrochimica Acta, 52, 7746 (2007).

14. L. Peguet, B. Malki, and B. Baroux, Corrosion Sci., 49,1933 (2007).

15. M. de O. Silva and H. Ferreira G. de Abreu and V. Hugo C de Albuquerque, P. de Lima Neto, and J. Manual R. S. Tavares, Materials and Design, 32, 605 (2011)

16. V. Vignal, C. Valot, R. Oltra, M. Verneau, and L. Coudreuse, Corrosion Sci., 44, 1477 (2002).
17. C. M. Rangel, T. M. Silva, and M. da Cunha Belo, Electrochimica Acta, 50, 5076 (2005).

18. L. F. Lin, C. Y. Chao, and D. D. Macdonald, J. Electrochem. Soc., 128, 1194 (1981).

19. A. Nazarov and D. Thierry, Electrochimica Acta, 52, 7689 (2007).

20. N. Fuertes Casals, A. Nazarov, F. Vucko, R. Pettersson, and D. Thierry, J. Electrochem. Soc., 162, C465 (2015).

21. D. Sidane, O. Devos, M. Puiggali, M. Touzet, B. Tribollet, and V. Vivier, Electrochemistry Communications 13, 1361 (2011)

22. J. Hölzl and F. K. Schulte, in "Solid Surface Physics", p.9, Springer - Verlag, Berlin Heidelberg, New York (1979).

23. S. Trasatti and R. Parsons, J. Electroanalytical Chem. 205, 359 (1986).

24. R. Hausbrand, M. Stratmann, and M. Rohwerder, J. Electrochem. Soc., 155, C369 (2008).

25. M. Stratmann and H. Streckel, Corrosion Science, 29, 687 (1990).

26. G. Grundmeier and M. Stratmann, Apply Surface Science, 141, 43 (1999).

27. I. Frateur, V. M-W. Huang, M. E. Orazem, B. Tribollet, and V. Vivier, J. Electrochem. Soc., 154, C719 (2007)

28. F. Zou, D. Thierry, and H. S. Isaacs, J. Electrochem. Soc., 144, 1957 (1997).

29. V. M.-W. Huang, S-L. Wu, M. E. Orazem, N. Pébère, B. Tribollet, and V. Vivier, Electrochim. Acta, 56, 8048 (2011).

30. V. Maurice, W. P. Yang, and P. Marcus, J. Electrochem. Soc. 143, 1182 (1996).

31. Y. Zhu, Y. Zhou, J. Lu, and W. G. Qin, Materials Chemistry and Physics, 118, 12 (2009).

32. Wen Li, Y. Wang, and D. Y. Li, Phys. stat. sol. (a), 201, 2005 (2004).

33. X. F. Wang, W. Li, J. G. Lin, and Y. Xiao, A letters Journal Exploring the Frontiers of Physics, 89, 66004 (2010).

34. R. J. Wang, J. X. Li, Y. J. Su, L. J. Qiao, and A. A. Volinsky, Procedia Materials Science, 3, 1736 (2014).

35. H. Wagner in: "Physical and Chemical Properties of stepped surfaces", J. Hölzl, F. K. Schulte, and H. Wagner (Eds.) p.182, Solid Surface Physics, Springer-Verlag, Berlin Heidelberg, New York (1979).

36. V. Vignal, R. Oltra, M. Verneau, and L. Coudreuse, Mater. Sci. Eng. A303, 173 (2001).

37. N. E. Hakiki, J. Appl. Electrochem. 38, 679 (2008).

38. N. Sato, Physical concept of single electrode potential, Materials Sci. Forum, 185188, 397 (1995)

39. A. Kiejna and V. V. Pogosov, Phys. Rev. B, 62, 10445 (2000).

40. X. Feng, X. Lu, Yu Zuo, and Da Chen, Corrosion Sci. 82, 347 (2014).

41. L. Jinlong and L. Hongyun, Applied Surface Science, 263, .29 (2012).

42. G. Bambara, Corrosion Sci. 19, 991 (1979).

43. Y. Huang, F. Xuan, Shan-Tung Tu, and T. Itoh, Materials Science and Enginiring A, 528, 1882 (2011).

44. F. Navai, J. of Material Sci. 35, 5921 (2000). 